\title{
Pharmakoresistenz findet auf vielen Ebenen statt
}

\author{
Das Phänomen Pharmakoresistenz bei der Epilepsie ist ein multifaktorielles Problem. Eine der möglichen \\ rsachen kann die vermehrte Ausschleusung von Medikamenten aus der Zielzelle durch entsprechende \\ Transporterproteine sein.
}

$\mathrm{N}$ turen für die Antiepileptika - wie für den Natriumkanal Nav1.1 gezeigt (siehe vorige Seite) - kann auch die Hochregulation eines Proteins Ursache für eine fehlende Medikamentenwirkung sein. So wurde eine anfallsgetriggerte vermehrte Expression von Effluxtransportern wie dem P-Glykoprotein (PGp) ABCB1 beschrieben, die Medikamente wieder aus den Zielzellen herausschleueben Mutationen in den Zielstruk-

sen können. Es gibt sowohl experimentelle als auch klinische Hinweise, dass diese Hochregulation bei pharmakoresistenten Patienten stärker ausgeprägt ist als bei Respondern (Abbildung 1). Für die funktionelle Relevanz dieses Phänomens spricht auch die Tatsache, dass eine experimentelle PGp-Modulation die Pharmakosensitivität wiederherstellen kann. Antiepileptika wie Lamotrigin, Levetiracetam und Oxcarba-

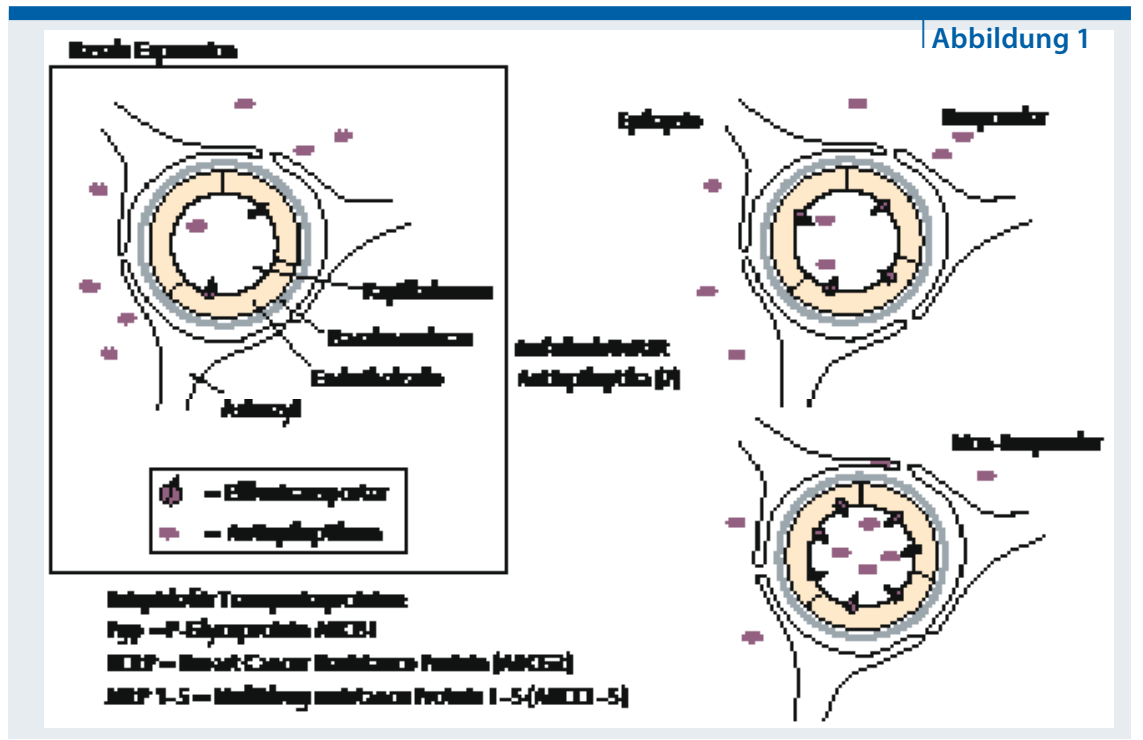

Non-Responder haben mehr Medikamente ausschleusende Transporterproteine [1]. zepin, ebenso wie aktive Metaboliten von Carbamazepin und Oxcarbazepin, wurden als Substrate dieser Transportproteine identifiziert. Die Inhibition von PGp erscheint nicht sinnvoll, da diese physiologischerweise für protektive Aufgaben im Organismus zuständig sind. Dagegen erwies sich ein präventiver Ansatz durch COX-2- Hemmstoffe in Epilepsie-Modellen als erfolgreich zur Kontrolle der PGp-Überexpression und zur Überwindung der Pharmakoresistenz.

Auch auf der Ebene der Blut-HirnSchranke sind heute mehrere Epilepsieassoziierte Veränderungen bekannt. So findet anfallsgetriggert eine vermehrte Transzytose über Endothelzellen statt, sodass Plasmaproteine gehäuft in den Extrazellularraum des Gehirns gelangen. Die Konsequenz: Antiepileptika binden verstärkt an diese Plasmaproteine; es steht weniger freier Wirkstoff für die Interaktion mit der Zielstruktur zur Verfügung.

Dr. Katharina Arnheim

\section{Potschka H. Pharmacogenomics. 2010; 11 (10): $1427-38$}

Vortrag von Professor H. Potschka bei der 8. Gemeinsamen Jahrestagung der Deutschen und Österreichischen Gesellschaften für Epileptologie und der Schweizerischen Liga gegen Epilepsie, Interlaken/Schweiz, 8.-11.5.2013

\section{Homevideos - neues Hilfsmittel im Epilepsie-Management}

In der Diagnostik und Verlaufsbeobachtung von Epilepsien gewinnen Homevideos zunehmend an Bedeutung. Man versteht darunter im häuslichen Umfeld aufgenommene Videos zur Dokumentation anfallsartiger Zustände bei sich selbst oder anderen.

D ie sogenannten Homevideos können heute leicht mithilfe digitaler Kameras oder Smartphones realisiert werden. Sie werden anschließend dem Behandler zugesandt oder zwecks Auswertung in die Sprechstunde mitgebracht. Gut geeignet sind Homevideos - eine ausreichende Qualität vorausgesetzt - zur
Diagnosesicherung seltener oder bisher nicht geklärter Anfallszustände und zur Differenzialdiagnose epileptischer und nicht epileptischer Anfallsleiden. Sie können aber auch zur Dokumentation von Nebenwirkungen und Verhaltensbesonderheiten oder gänzlich neuer Anfälle genutzt werden.
Laut einer Auswertung von Professor Thomas Mayer, Kleinwachau, Sächsisches Epilepsie-Zentrum Radeberg, brachten 26 von 822 Patienten mit Anfallsleiden, überwiegend Epilepsie (96\%), eigene Homevideos in die Sprechstunde mit. In 14 Fällen handelte es sich um neue Patienten, sodass das 